\title{
PAKETLİ BALLARIN BOTANİK ORİJİN TESPİTİ VE MİKROSKOBİK ANALİZLERİ: ETİKET BİLGİLERİ İLE İÇERİK UYUMLULUĞUNUN KARŞILAŞTIRILMASI
}

\author{
Çiğgdem Özenirler ${ }^{1,2} *$, Nazlı Mayda ${ }^{1}$, Ömür Gençay Çelemlii, \\ Aslı Özkök ${ }^{2}$, Kadriye Sorkun ${ }^{1,2}$ \\ ${ }^{1}$ Hacettepe Üniversitesi, Fen Fakültesi, Biyoloji Bölümü, Beytepe, Ankara-Türkiye \\ ${ }^{2}$ Hacettepe Üniversitesi Ar1 ve Arı Ürünleri Uygulama ve Araştırma Merkezi, Beytepe, Ankara-Türkiye
}

Geliş / Received: 14.03.2019; Kabul / Accepted: 18.08.2019; Online bask1 / Published online: 04.09.2019

Özenirler, Ç., Mayda, N., Gençay Çelemli, Ö., Özkök., A., Sorkun, K. (2019). Paketli balların botanik orijin tespiti ve mikroskobik analizleri: etiket bilgileri ile içerik uyumluluğunun karşılaştırılması. GIDA (2019) 44 (5): 861-865 doi: 10.15237/gida.GD19058

Özenirler, C., Mayda, N., Gençay Celemli, Ö., Özkök., A., Sorkun, K. (2019). Botanic origin detection and microscopic analysis of packaged honeys: comparison of content with label information. GIDA (2019) 44 (5): 861-865 doi: 10.15237/gida.GD19058

\section{ÖZ}

Bal, çiçekli bitkilerin nektarlarından ya da bitki özsuyu ile beslenen böceklerin salgilarından köken alır. İçeriğindeki polen ve bal çiği elementlerinin tanımlanması, balın botanik kökeninin belirlenmesinde kullanılan en önemli araçlardır. Türk Gıda Kodeksi Bal Tebliğ̣’ne göre gıda maddesi olarak tüketime sunulacak balların botanik kökeninin standartlar çerçevesinde yapılan analizler ile tespit edilmesi ve paket üzerindeki etiket ile alıcların bilgilendirilmesi gerekir. Bu çalışmada Türkiye'de satışa sunulmuş paketli balların mikroskobik analizleri gerçekleştirilerek elde edilen sonuçların etiket bilgisi ile uyumluluğunun karşılaştırlması amaçlanmıştır. $\mathrm{Bu}$ kapsamda balların polen kompozisyonları, bal çiği elementleri (BÇE), 10 gram baldaki toplam polen sayısı (TPS$10 \mathrm{~g}$ ) ve bal çiği elementi sayıları, yüzde nem ve nişasta miktarı incelenmiştir. Sonuç olarak tüm bal örneklerinin nem değerlerinin tebliğde verilen değerlerle uyumlu olduğu tespit edilmiştir. Mikroskobik incelemeler sonucunda 10 balın etikette yer alan botanik orijini ile uyum göstermediği, üç balda $\% 10$ 'dan fazla nişasta bulunduğu saptanmıştır.

Anahtar kelimeler: Piyasa balları, botanik orijin, kalite

\section{BOTANIC ORIGIN DETECTION AND MICROSCOPIC ANALYSIS OF PACKAGED HONEYS: COMPARISON OF CONTENT WITH LABEL INFORMATION}

\begin{abstract}
Honey originates from the nectars of flowering plants or excretions of plant-sucking insects on plants. The identification of pollen and honeydew elements is the most important tool used to determine the botanical origin. According to the Turkish Food Codex Communiqué on Honey, it's necessary to determine the botanical origin of the honey to inform the buyers with the label on the package. Our aim was to detect the botanic origin and comparison with their label information content compliance of packaged honeys produced in Turkey. In this context, pollen compositions of honeys, the number of honeydew elements, total number of pollen and honeydew elements in 10 grams of honey, percentage of moisture and starch were examined. As a result, moisture values were found suitable. 10 honeys didn't match with the botanical origin declared in the label, and in three honey samples more than $10 \%$ starch was found.
\end{abstract}

Key words: Packed honeys, botanical origin, quality

\footnotetext{
${ }^{*}$ Yazışmalardan sorumlu yazar/ Corresponding author

$\triangle$ cozenir@hacettepe.edu.tr, $\quad$ (+90) 03122978055

㚗 $(+90) 3122992028$
} 


\section{GİRİ̧̧}

Bal; bitkilerin çiçeklerinde veya diğer canlı kısımlarında bulunan nektaryumlardan salgilanan nektarlardan, ya da bitki özsuyu ile beslenen böceklerin salgilarından köken alır (Anklam, 1998). Karbonhidrat kaynağ 1 olan bu tatli salgilarin bal arilarinca toplanmasi, arinin vücudunda değişik enzimlerle metabolize olması ve petek gözlerine depolanması, suyunun uçurulması ve olgunlaşması ile arıların ve insanoğlunun da besin maddesi olarak kullandığ1 bal üretimi gerçekleşir (Sorkun, 2008).

Balın sinıflandırılması, arıların balın kökenini oluşturan maddeyi topladıkları kaynak göz önünde bulundurularak yapılır. Bu kapsamda bal, çiçek ve salgı balı olarak iki genel sınıfta incelenir (Moar, 1985). Çiçek balının kökeni nektar, salg1 balının kökeni ise bitkilerin canlı kısımlarının salg1ları ve/veya bitkilerin canlı kısımları üzerinde yaşayan bitki özsuyu emici böceklerin salg1larıdır (Anonim, 2012).

Balın kaynağını belirlemek için kullanılan geleneksel yöntem, balların mikroskobik olarak değerlendirilmesine dayanır. Buradaki temel prensip balın kökenini dolaylı yoldan tespit etmektir. Balların üretimi sırasında arıların ziyaret ettiği bitkileri belirlemek için bal içindeki polenlerin tanımlanması (Soares vd., 2015) ve salg1 kökenli balların mikroskobik analizlerinde bal çiği elementi olarak nitelendirilen spor, hif ve alglerin tespiti ve bu verilerin sayisal olarak değerlendirilmesi söz konusudur (Louveaux vd., 1978). Polen taneleri, çoğunlukla nektarlı bitkilerden, bal arılarının diyetinin amino asit, yağ asidi ve mineral ihtiyacını karşılamak için gerçekleştirilen yiyecek arama davranışları sırasında taşınır (Yang vd., 2013; Avni vd., 2014; Belay vd., 2017).

Balda tespit edilen taksanın polenlerinin yüzdeleri hesaplanarak dominat $(\% 45 \leq \mathrm{x})$, sekonder $(\% 16$ $\leq \mathrm{x} \leq \% 44)$, minör $(\% 4 \leq \mathrm{x} \leq \% 15)$ ve eser $(\% 3$ $\leq \mathrm{x}$ ) olmak üzere dört faklı kategoride balların bitki kaynakları kategorize edilir (Pérez-Arquillué vd., 1995). Herhangi bir balın monofloral (tek bir bitkisel kaynaktan köken almış) olarak nitelendirilebilmesi için bahsi geçen bitkiye ait polenlerin, mikroskobik incelemeler sonucunda, balda dominant halde bulunduğunun tespit edilmesi gerekir (Day vd., 1990). Balın polen içeriğinin belirlenmesi, sahteciliğin tespiti için kullanılmakta olan önemli araçlardandır (Bayram ve Demir 2018).

Mikroskobik incelemeler sonucunda tespit edilen 10 gram baldaki bal çiği elementi (BÇE) sayısı ile toplam polen say1s1 (TPS-10 g) oranlar1 da salg1 balını kendi içinde kategorize edebilmemize yardımcı olur. BÇE/TPS-10 g oranının 1.5-3.0 değerleri arasında olması balın salg1-çiçek karışık bal olduğunu, 3.0-4.5 değer aralı̆ı̆nda olması yoğun çam balı olduğunu gösterirken, bu oran $>4.5$ şeklinde ifade buluyorsa da çok kaliteli çam balı olarak nitelendirilir (Sorkun, 2008).

Balın paketlenmesi ve etiketlenmesi aşamasında Türk Gıda Kodeksi Bal Tebliği çerçevesinde konulmuş kurallar bulunur. Etikette balın orijini; salg1 veya çiçek balı olduğu, bal ifadesinin yanında aynı punto ile belirtilir. Etiketinde botanik orijini belirtilen ballarda bu özellikleri polen analizi ile belirlenir. Nişasta/polen oranının maksimum 10/100 olmas1 gerekir. Balın ihtiva ettiği nem miktarının en fazla \% 20 olması beklenir (Anonim, 2012).

$\mathrm{Bu}$ çalş̧mada hedefimiz paketlenmiş ve hâlihazırda marketlerde satılmakta olan ballardan alınan 29 örneğin mikroskobik analizleri, botanik orijinlerinin tespit edilmesi ve etiket bilgisi ile içerik uyumluğunun karşılaştırılmasıdır.

\section{MATERYAL VE YÖNTEM \\ Bal Örnekleri}

Araştırmada kullanılan materyal, 2017 yılında marketlerde satılmakta olan ballar arasindan alınmıştır. Etiketleri üzerinde yapılan tanımlamalar doğrultusunda, 21 çiçek balı ve 8 salg1 balı olmak üzere 29 örnek üzerinde incelemeler yapılmıştır. Çiçek ballarının dört tanesi petekli baldır.

\section{Balın Mikroskobik Analizi}

Balın mikroskobik analizi için iki farklı yöntem ile preparasyon işlemleri gerçekleştirilmiştir. Bunlardan birincisi balda polen analizi, diğeri ise 
baldaki toplam polen ya da bal çiği elementi sayısını belirleme analizidir. Polen analizi için hazırlanan preparatlarda nişasta sayımı da yapılmıstır.

\section{Balda polen analizi için preparasyon işlemleri} Sorkun (2008) metodu ile preparasyon yapılmıştır. Bu kapsamda cam baget yardımıyla stok baldan 10 $\mathrm{g}$ alınıp deney tüpüne aktarılmış ve üzerine $20 \mathrm{~mL}$ distile su ilave edilmiştir. Balın su içerisinde çözülmesini sağlamak amacıyla tüpler yaklaşık sicaklığ1 $45^{\circ}$ C'lik su banyosunda 20-25 dakika bekletilmiş ve su banyosundan çıkarılan tüp karıştırıcı yardımı ile karıştırılmıştır. Çözelti 3500 rpm'de $45 \mathrm{dk}$ santrifüj edilmiş ve santrifüj edilen tüplerin süpernatant k1smı dökülmüştür. İğne ucuna alınan bir miktar (1-2 $\left.\mathrm{mm}^{3}\right)$ bazik fuksinli gliserin-jelatinin dipteki çökeltiye bulaştırılmasıyla alınan materyal lam üzerine aktarılmış, bu materyalin isitma tablasinda $30-40^{\circ} \mathrm{C}^{\prime}$ de 1 sitilarak erimesi sağlanmıştır. Eriyen kısmın üzerine 18x18 mm'lik lamel kapatılarak ters çevrilip preparatın kuruması sağlanmıştır. Hazırlanan preparat yaklaşı 12 saat bu şekilde bekletildikten sonra incelemeye hazır hale gelmiştir. Polen sayımları, Nikon Eclipse E400 mikroskobu kullanılarak yapılmışır.

\section{Balların toplam polen sayısının ve bal çiği elementi sayılarının belirlenmesi için preparat hazirlanmasi}

Toplanan bal örneklerinde TPS ve BÇE, Moar (1985) ve Sorkun (2008)'un bildirdiği metoda göre hazırlanıp 1şı mikroskobunda incelenmiştir. Homojen hale getirilmiş stok baldan $10 \mathrm{~g}$ alınmış ve deney tüpüne aktarılmıştır. Örneğin üzerine 20 $\mathrm{mL}$ distile su ilave edilerek tüp içerisine şahit olarak bir tanesine 9666 adet Lycopodium spp. sporu içeren tablet atılmıştır. Tabletin erimesini sağlamak amaciyla tüpler $45 \mathrm{C}^{\circ}$ lik su banyosunda bekletilmiştir. Tablet eridikten sonra polenlerin ve sporların boyanmasını sağlayan iki damla bazik fuksin ilave edilmiştir. Tüpler $3500 \mathrm{rpm}$ 'de $45 \mathrm{dk}$ santrifüj edilmiştir. Santrifüj edilen tüplerin süpernatant kısm1 dökülmüștür. Tüpün içerisine $0.1 \mathrm{~mL}$ kadar \%50’lik gliserin ilave edilerek dipteki çökeltinin gliserin ile homojen bir biçimde karışması sağlanmıştır. Bu karışımdan pipetle 0.01 $\mathrm{mL}$ alınarak, $0.09 \mathrm{~mL} \% 50$ 'lik gliserin konulmuş başka bir tüpe aktarılmıştır. Bu tüpteki çözeltiden $0.01 \mathrm{~mL}$ alınarak lam üzerine konulmuş ve üzerine lamel kapatılarak mikroskopta incelenmeye hazır hale getirilmiştir.

Hazırlanan preparatlar, Nikon Eclipse E400 marka mikroskopta incelenmiş olup 18x18 mm'lik alan tamamen taranmıştır. Bu alanda bulunan tüm polenler, bal çiği elementleri ve Lycopodium spp. sporlar1 sayisal olarak tespit edilmiştir. Sayilan spor ve polenlerden "saynlan polen sayısı x 9666 /saynlan Lycopodium sporu” formülü ile TPS bulunmuştur.

\section{Refraktometre ile Nem Tayini}

Baldaki nem miktarı, Bogdanov vd. (1997) ve Devillers vd. (2004)'nin uyguladığı metoda göre, taşınabilir refraktometre aracillğı ile tespit edilmiştir. Buna göre, cam baget ile alınan yaklaşık $1 \mathrm{~g}$ bal, refraktometrenin cam bölmesine konulmuştur. Nemin miktarı mercekli kısımdan bakılarak \% olarak ifade edilmiştir.

\section{BULGULAR VE TARTIŞMA}

Balın polen analizi sonuçlarına göre yapılan sinıflandırma, TPS-10 g, BÇE/TPS-10 g, nem ve nişasta başlıkları altında yapilan değerlendirmeler sonucunda elde edilen bulgular Çizelge 1'de verilmiştir.

Tüm bal örneklerinin nem değerlerinin \%13.5 $\% 18.3$ aralığında değerler ile temsil edildiği saptanmış olup, Türk Gıda Kodeksi Bal Tebliği'ne uygun oldukları tespit edilmiştir. Mikroskobik incelemeler sonucunda, BÇE/TPS-10 $\mathrm{g}$ bulguları doğrultusunda, 19 balın etiket bilgisi ile uyumlu olduğu, 10 balın ise etikette yer alan botanik orijini ile uyum göstermediği bulunmuştur. Dört adet petekli çiçek balı, polen içeriği bakımından karışık çiçek balı olarak sinıflandırılmıştır. Ancak bu ballardan bir tanesinin etiketinde yer alan "akasya" ibaresi, balın monofloral bir bal olduğunun bilgisini verirken, polen analizi sonuçları balın multifloral kaynaklı olduğunu göstermiştir. 7 adet bal süzme çam balı, bir adet bal ise süzme salg1 balı olarak etiketlenmiştir. Toplamda 8 adet olan salg1 balından, yalnızca bir tanesinin çam balı kriterlerine uygun olduğu, 5 tanesinin orta yoğun çam ve çiçek balı, 2 tanesinin ise az yoğun çiçek 
balı olduğu bulunmuştur. Etiket bilgileri ile ilgili uyumsuzluğun çam ve çiçek ballarının karıştırılarak satılmasından kaynaklandığı düşünülmektedir. 16 adet süzme çiçek balı olarak etiketlenmiş balın 14'ünün karışı çiçek balı, 1 tanesinin yoğun çam balı ve bir diğerinin ise eser bal çiği elementi içeren karışık çiçek balı olduğu tespit edilmiştir. Bir adet süzme kestane balı etiketli ürünün polen içeriğinin \%93’ünün kestane olduğu bulunmuş ve etiket bilgisi ile uyumluluğu onaylanmıştır. Üç balda \%10'dan fazla nişasta bulunduğu saptanmıştır.

Çizelge 1. Bal örneklerinin etiket bilgisi, polen analiz sonuçlanı, TPS-10 g, BÇE/TPS-10 g, nem ve nişasta değerleri

Table 1. Label information of honeys, pollen compositions, total number of pollen in 10 grams of honey (NTP-10 g), the number of honeydew element (NHE)/NTP-10 g, percentage of moisture and percentage of starch in honey

\begin{tabular}{|c|c|c|c|c|c|}
\hline $\begin{array}{l}\text { Etiket Bilgisi } \\
\text { Label Information }\end{array}$ & $\begin{array}{l}\text { Polen Analizi Sonuçları } \\
\text { Pollen Analysis Results }\end{array}$ & $\begin{array}{l}\text { TPS-10 g } \\
\text { TPN-10g }\end{array}$ & $\begin{array}{l}\text { BÇE/TPS-10 g } \\
H D E / T P N-10 g\end{array}$ & $\begin{array}{c}\mathrm{Nem} \\
(\%) \\
\text { Moisture } \\
(\%) \\
\end{array}$ & $\begin{array}{c}\text { Nişasta } \\
(\%) \\
\text { Starch } \\
(\%)\end{array}$ \\
\hline $\begin{array}{l}\text { Petekli Çiçek Balı } \\
\text { Comb Flower Honey }\end{array}$ & $\begin{array}{l}\text { Karışık Çiçek Balı } \\
\text { Mix Flower Honey }\end{array}$ & 20642 & - & 15.9 & 0 \\
\hline $\begin{array}{l}\text { Petekli Ciccek Balı } \\
\text { Comb Flower Honey }\end{array}$ & $\begin{array}{l}\text { Karışık Çiçek Balı } \\
\text { Mix Flower Honey }\end{array}$ & 2612 & - & 15.7 & 0 \\
\hline $\begin{array}{l}\text { Petekli Çiçek Balı } \\
\text { Comb Flower Honey }\end{array}$ & $\begin{array}{l}\text { Karışık Çiçek Balı } \\
\text { Mix Flower Honey }\end{array}$ & 1247 & - & 13.5 & 0 \\
\hline $\begin{array}{l}\text { *Petekli Çiçek Balı (Akasya) } \\
\text { Comb Flower Honey (Acacia) }\end{array}$ & $\begin{array}{l}\text { Karışık Çiçek Balı } \\
\text { Mix Flower Honey }\end{array}$ & 6444 & - & 16.5 & 80 \\
\hline $\begin{array}{l}\text { *Süzme Çam Balı } \\
\text { Drained Pine Honey }\end{array}$ & $\begin{array}{l}\text { Orta Yoğun, Çam } \\
\text { +Çiçek Balı } \\
\text { Medium Dense, Pine } \\
\text { +Flower Honey }\end{array}$ & 13367 & 2.8 & 17.4 & 5 \\
\hline $\begin{array}{l}\text { *Süzme Çam Balı } \\
\text { Drained Pine Honey }\end{array}$ & $\begin{array}{l}\text { Az Yoğun, Çiçek Balı } \\
\text { Less Intense, Flower Honey }\end{array}$ & 37137 & 0.51 & 17 & 0 \\
\hline $\begin{array}{l}\text { *Süzme Çam Balı } \\
\text { Drained Pine Honey }\end{array}$ & $\begin{array}{l}\text { Az Yoğun, Çiçek Balı } \\
\text { Less Intense, Flower Honey }\end{array}$ & 39113 & 0.63 & 16.8 & 0 \\
\hline $\begin{array}{l}\text { Süzme Çam Balı } \\
\text { Drained Pine Honey }\end{array}$ & $\begin{array}{l}\text { Yoğun Çam Balı } \\
\text { Dense Pine Honey }\end{array}$ & 68540 & 3 & 17.4 & 0 \\
\hline $\begin{array}{l}\text { *Süzme Çam Balı } \\
\text { Drained Pine Honey }\end{array}$ & $\begin{array}{l}\text { Orta Yoğun, Çam } \\
\text { + Çiçek Balı } \\
\text { Medium Dense, Pine } \\
\text { +Flower Honey }\end{array}$ & 110192 & 2.8 & 18.3 & 0 \\
\hline $\begin{array}{l}\text { *Süzme Çam Balı } \\
\text { Drained Pine Honey }\end{array}$ & $\begin{array}{l}\text { Orta Yoğun, Çam } \\
\text { +Çiçek Balı } \\
\text { Medium Dense, Pine } \\
\text { +Flower Honey }\end{array}$ & 45913 & 2.3 & 17.9 & 0 \\
\hline $\begin{array}{l}\text { * Süzme Çam Balı } \\
\text { Drained Pine Honey }\end{array}$ & $\begin{array}{l}\text { Orta Yoğun, Çam } \\
\text { + Çiçek Balı } \\
\text { Medium Dense, Pine } \\
\text { + Flower Honey }\end{array}$ & 19332 & 1.56 & 17.1 & 0 \\
\hline $\begin{array}{l}\text { *Süzme Çiçek Balı } \\
\text { Drained Flower Honey }\end{array}$ & $\begin{array}{l}\text { Yoğun Çam Balı } \\
\text { Dense Pine Honey }\end{array}$ & 9666 & 3.6 & 18.1 & 1 \\
\hline
\end{tabular}

* Etiket bilgileri ile polen analizi sonuçları uyuşmayan bal örnekleri

*Honeys which are not match with the botanical origin declared in the label

TPS-10 g: Toplam polen sayis1, TPN-10 g: Total Pollen Number

BÇE: Bal çiği elementi, HDE: Honeyden Element 
Türkiye'nin altı farklı bölgesinde bulunan çeşitli illerdeki büyük ve küçük ölçekli marketlerden toplanan 47 adet süzme bal örneği yapılan bir çalışmada incelenmiştir. Monofloral ballarda yanlış etiketleme tespit edilen çalışmada, 47 adet bal örneğinden, 7 örnekte Nosema sp. sporlar1 değişik yoğunluklarda bulunmuştur (Bölükbaş1, 2009).

Yapılan kısıtlı sayıda çalışma, ülkemizde paketli olarak satışa sunulan ballarda etiket bilgileri ve genel içerik durumları ile ilgili olarak tüketicilerde güvensizliğe yol açacak uygulamaların olduğunu göstermektedir. Nektar ya da salgidan kovana, kovandan sofralara gelinceye kadar yaşanan süreçte geçirilen dönüşüm değerlendirildiğinde, her ne kadar pek çok noktada gıda olarak tüketilen bu ürünün kontrolü yapilıyor olsa da, vardığımız sonuçlar belli düzeylerdeki sıkıntıların göstergesi olarak sunulmuştur. Balın kaynağ1 ile ilgili olarak üreticiden alınan sözlü bilgi yerine, polen analizlerinin yapılarak etiketleme işlemlerinin gerçekleştirilmesi gerekmektedir. Bu çerçevede, balın botanik orijinin belirlenmesi aşamasında daha sık1 denetimlerinin yapılması gerektiği düşünülmektedir.

\section{KAYNAKLAR}

Anklam, E. (1998). A review of the analytical methods to determine the geographical and botanical origin of honey. Food Chem, 63: 549-562.

Anonim (2012). Türk gida kodeksi. Bal tebliği (2012/58). Tarım ve Orman Bakanlığı. 27 Temmuz 2012 tarih ve 28366 sayllı Resmî Gazete, Ankara.

Avni, D., Hendriksma, H.P., Dag, A., Uni, Z., Shafir, S. (2014). Nutritional aspects of honey bee-collected pollen and constraints on colony development in the eastern Mediterranean. J Insect Physiol, 69: 65-73.

Bogdanov, S., Martin, P., \& Lüllmann, C. (1997). Harmonised methods of the European honey commission. Apidologie (France).

Bayram, N.E., Demir, E. (2018). Specifying some quality characteristics of monofloral and multifloral honey samples. Hacettepe J Biol \& Chem, 46: 417-423.

Belay, A., Haki, G.D., Birringer, M., Borck, H., Addi, A., Baye, K., Melaku, S. (2017). Rheology and botanical origin of Ethiopian monofloral honey. Lwt-Food Sci Technol, 75: 393-401.

Bölükbaşı, D.N. (2009). Melissopalynologic analysis of packed honey. Mellifera, 9: 2-8.

Day, S., Beyer, R., Mercer, A., Ogden, S. (1990). The nutrient composition of honeybee-collected pollen in Otago, New Zealand. J Apic Res, 29: 138146.

Devillers, J., Morlot, M., Pham-Delegue, M. H., \& Dore, J. C. (2004). Classification of monofloral honeys based on their quality control data. Food Chem, 86(2): 305-312.

Louveaux, J., Maurizio, A., \& Vorwohl, G. (1978). Methods of melissopalynology. Bee World, 59(4): 139-157.

Moar, N. (1985). Pollen analysis of New Zealand honey. N Z J Agric Res, 28: 39-70.

Pérez-Arquillué, C., Conchello, P., Ariño, A., Juan, T., Herrera, A. (1995). Physicochemical attributes and pollen spectrum of some unifloral Spanish honeys. Food Chem, 54: 167-172.

Soares, S., Amaral, J.S., Oliveira, M.B.P., Mafra, I. (2015). Improving DNA isolation from honey for the botanical origin identification. Food Control, 48: 130-136.

Sorkun, K., (2008). Türkiye'nin Nektarl Bitkileri, Polenleri ve Ballar. Palme Yayınları: 462, Ankara, Türkiye, 341s.

Yang, K., Wu, D., Ye, X., Liu, D., Chen, J., Sun, P. (2013). Characterization of chemical composition of bee pollen in China. J Agric Food Chem, 61: 708-718. 